\title{
THE INFLUENCE OF VAGINAL SUPPOSITORIES "MELANIZOL" ON THE SYSTEM OF LPO-AOS IN CONDITION OF MODEL OF A NONSPECIFIC VAGINITIS IN RATS
}

\author{
Olena Dolzhykova \\ Department of Clinical Laboratory Diagnostics ${ }^{l}$ \\ dolzhikova.elena20@gmail.com \\ Ludmila Maloshtan \\ Department of Physiology and Human Anatomy ${ }^{l}$ \\ ${ }^{1}$ National University of Pharmacy \\ 53 Pushkinska str., Kharkiv, Ukraine, 61002 \\ lnm004@gmail.com
}

\begin{abstract}
It is known that almost any pathology is accompanied by an imbalance of the lipid peroxidation (LPO) and the antioxidant system (AOS), and diseases of the female reproductive system are no exception. Thus, modern therapies of nonspecific vaginitis (NV) should include drugs with an antioxidant effect in the complex treatment, because the role of the LPO-AOS system in the mechanism for the development of NV is great. This problem can be solved by new complex drug with plant material with a wide spectrum of action.

Aim. The aim of our research was to study the effect of new vaginal suppositories "Melanizol", containing metronidazole and tea tree oil on the system of LPO-AOS on a model of nonspecific vaginitis in rats.

Materials and methods. The study object was the new vaginal suppositories "Melanizol". As reference drugs there were taken suppositories "Gravagin" and "Hippophaes oleum suppositories". The study has been carried out on the model of experimental nonspecific (irritative) vaginitis caused in rats by the mixture of turpentine oil and dimethyl sulfoxide. Blood serum and vaginal tissue were used as the material for the study. Thiobarbituric acid-active products (TBA-AP) were determined as the component of a lipid peroxidation. The catalase (CAT), the superoxide dismutase (SOD) and the reduced glutathione (G-SH) were determined as the component of an antioxidant system.

Results and discussion. On the background of experimental vaginitis in serum and in vaginal tissue homogenate in rats, significant changes in indicators of the LPO-AOS were noted. Change of these indicators show a systemic response of the body to pathological changes in the vagina, which is manifested in the depletion of AOS and activation of the LPO. The vaginal suppositories "Melanizol" in the study on the model of nonspecific (irritative) vaginitis in rats showed an antioxidant effect. Suppositories "Melanizol" significantly reduce the level of TBA-AP, interfering with lipid peroxidation processes, and restore the level of G-SH, as well as the activity of SOD and catalase in the blood and in the vaginal homogenate, helping to protect the cell membranes. Suppositories "Melanizol" significantly exceed the reference suppositories "Gravagin" and are not inferior to the reference drug "Hippophaes oleum suppositories" in activity to reduce the level of TBA-AP, and to restore the level of G-SH, as well as restoration the activity of SOD and CAT. Antioxidant activity of vaginal suppositories "Melanizol" can be explained by the presence of tea tree oil and metronidazole in their composition, which is confirmed by literature data.

Conclusions. The conducted researches have shown that the new vaginal suppositories "Melanizol" demonstrated antioxidation activity. Results of this experiment allow us to recommend them for the further studies as medication for the treatment of nonspecific vaginitis.
\end{abstract}

Keywords: vaginal pessaries, vaginitis, metronidazole, tea tree oil, antioxidant activity, lipid peroxidation, rats.

DOI: $10.21303 / 2504-5679.2019 .00998$

\section{Introduction}

In recent years the study of the role of lipid peroxidation (LPO) and the antioxidant system (AOS) in the pathogenesis of many diseases has been of interest to researchers. It is known that almost any pathology is accompanied by an imbalance of the LPO-AOS system, and diseases of the female reproductive system are no exception [1-3]. Also a change in the potential of LPOAOS in nonspecific vaginitis (NV) has been noted [3]. This is because NV is accompanied by an 
increase in the number of conditionally pathogenic microflora, which provokes the activation of polymorphonuclear leukocytes, as the first line of innate protection and the effector of adaptive immunity. Their release activates excessive inflammation and oxidative stress in the vagina, which leads to the production of reactive oxygen species (ROS) [4]. The formation of ROS activates the processes of LPO are a factors that damage a lot of cellular components (membrane lipids, enzymes, DNA, etc.) [5], leading to cell death.

A change in the level of thiobarbituric acid-active products (TBA-AP) is the result of the discrepancy between the capabilities of antioxidant enzymes and the rate of free radical oxidation [5], which also reflect the degree of damage of cell membranes under the action of ROS [6].

The state of AOS on the contrary displays the protective capabilities of the body and cell membranes from damage by free radicals [5].

Glutathione is one of the most studied antioxidants. It is an intracellular antioxidant with a powerful detoxifying effect. The glutathione system includes glutathione and three enzymes (glutathione peroxidase, glutathione transferase and glutathione reductase) and is the only one system in the body that participates in three of four lines of defense. The presence of a sufficient concentration of reduced glutathione is a critical factor in the survival of cells in oxidative stress [7].

Also, the functions of the antioxidant defense system are realized by enzymes superoxide dismutase (SOD) and catalase (CAT). Many inflammatory diseases are accompanied by changes in the activity of SOD and CAT in the blood [8]. Superoxide dismutase catalyzes the dismutation (or partitioning) of the superoxide radical - a product of one-electron reduction of molecular oxygen (to oxygen and hydrogen peroxide), which is formed in almost all body cells, that contact with oxygen. Superoxide radical plays a leading role in the processes of ROS toxicity [8]. Catalase removes toxic hydrogen peroxide $\left(\mathrm{H}_{2} \mathrm{O}_{2}\right)$, catalyzing its decomposition to $\mathrm{O}_{2}$ and $\mathrm{H}_{2} \mathrm{O}$ and prevents its accumulation. This highly active enzyme does not require energy to activate [3,9]. And its high activity is crucial to ensure the function of SOD [3].

Thus, modern therapies of NV should include drugs with an antioxidant effect in the complex treatment, because the role of the LPO-AOS system in the mechanism for the development of $\mathrm{NV}$ is great.

In most cases, along with the rest, local treatment of $\mathrm{NV}$ is effective. It creates a higher local concentration of drugs in vagina and decreases drug interactions and side effects. In addition, the resistance of microorganisms to antibiotics and the difficulties resulting from frequent relapses create the need for more effective new drugs with herbal material with a lot of range of effects [10].

The aim of our research was to study the effect of new vaginal suppositories "Melanizol", containing metronidazole and tea tree oil [11], developed at the Department of TL NUPh under the guidance of prof. T. G. Yarnykh on the LPO-AOS system on a model of nonspecific (irritative) vaginitis in rats.

\section{Materials and methods}

As studied drugs there were taken: suppositories "Melanizol" (1 pessary contains $250 \mathrm{mg}$ of metronidazole, $100 \mathrm{mg}$ of tea tree oil, the mixture of PEO-1500 and PEO-400 (9:1) As reference drugs there were taken: suppositories "Gravagin" (nonproprietary name, production of "Sperco Ukraine", Ukraine; 1 suppository contains $500 \mathrm{mg}$ of metronidazole), similar in composition to "Melanizol" and recommended in protocols for the treatment of gynecological diseases; "Hippophaes oleum suppositories" (nonproprietary name, production of "Nizhpharm", Russia; 1 suppository contains $500 \mathrm{mg}$ of oleum Hippophaes), to have antioxidant properties and are used in gynecological practice for the complex treatment of inflammatory processes of the vagina and cervix, as well as by erosion of the cervix.

The study was conducted on 36 non-linear white laboratory female rats weighing $190 \pm 20 \mathrm{~g}$. The animals were kept on a standard diet of the vivarium. Care of them (including euthanasia) during the experiment was carried out according to the requirements of documents, which regulate organization of the work with experimental animals. The principles of the "European Convention for the Protection of Vertebrate Animals used for experimental and other scientific purposes" were followed (Strasbourg, 18.3.1986) [12], adopted by The I National Congress on Bioethics (Kyiv, 2000), 
which is coordinated with the "European Convention for the Protection of Vertebrate Animals used for experimental and other scientific purposes", Council Directive 86/609/EEC of 24 November 1986 on the approximation of laws, regulations and administrative provisions of the Member States regarding the protection of animals used for experimental and other scientific purposes, Order of the Ministry of Health of Ukraine from February 13, 2006 No. 66, Law of Ukraine "On protection of animals from cruelty" (No. 3447-IV 21.02.2006). After completion of the experiment, the rats were taken out from the experiment in accordance with the ethical principles of animal testing.

Before the beginning of the experiment, the estrous cycle was examined in female rats and the animals in proestrus-estrus phases were selected, in order to minimize the differences in the assessment of the functional state of the vaginal mucosa when comparing the obtained results.

Nonspecific (irritative) vaginitis was modeled by a single intravaginal application of a mixture of irritants [13]: presented by the mixture of turpentine oil (JSC "Yantar", Ukraine) with dimethyl sulfoxide (Dimexid, "Arterium", JSC "Halychpharm", Ukraine) in the ratio of 1:1 at the dose of $0.5 \mathrm{ml} / 100 \mathrm{~g}$ of the body weight of the animal. The animals were divided into 6 groups of 6 animals in every group each as follows: $1^{\text {st }}$ group - intact animals (IC, intact control, no pathology), 2 group - control pathology (CP, positive control), 3 group - animals treated with vaginal suppositories "Melanizol", group 4 - animals treated with the reference vaginal suppositories "Gravagin"; group 5 - animals treated with the reference drug "Hippophaes oleum suppositories"; group 6 - animals, on which the pessary base in an equivalent amount was applied (placebo; negative control; the mixture of PEO-1500 and PEO-400 (9:1). Treatment began 24 hours after the application of the irritant. The studied drugs were being injected into the vagina during 7 days, once a day. The studied pessaries and reference drugs were injected vaginally once a day at doses calculated using the specific sustainability factors by Y. R. Rybolovliev, applied in the experimental pharmacology [14].

After finishing experiment, the animals were taken out from the experiment by the method of euthanasia. Blood serum and vaginal tissue were used as the material for the study. The determination of the components of LPO-AOS activity was performed on a spectrophotometer "SPEKOL 1500" (Germany). TBA-AP, CAT and SOD were determined in the serum [15]. CAT, TBA-AP and reduced glutathione (G-SH) were determined in the vaginal tissue [15].

Changes in these indicators allow us to assess the severity of the inflammatory process, in which a disbalance between the processes of LPO and the protective systems of the body is present. The content of TBA-AP - product reactive with thiobarbituric acid, most often determine as an indicator of intensity POL. Under their influence occurs damage of cell membrane. There is one of the leading factors in the development of the inflammatory process [6]. In turn, the state of the antioxidant system was assessed by the level of G-SH and the activity of intracellular antioxidant enzymes CAT and SOD [16].

Statistical treatment of the obtained results was carried out with the program "Statistica 6.0" (Free Trial Version https://www.tibco.com/), using the Newman-Keuls criterion, the data were considered reliable when the difference between the mean values $\mathrm{p}<0.05$.

\section{Research results}

Data on the effect of new vaginal suppositories "Melanizol" on the status of indicators of the LPO-AOS system in blood serum and vaginal tissue of rats on the background of experimental nonspecific (irritative) vaginitis are presented in Fig. 1, 2.

An imbalance in the LPO-AOC system in the vaginal tissue homogenate of rats was observed on the background of nonspecific (irritative) vaginitis (Fig. 1). The level of catalase was significantly reduced by almost 2 times the level of G-SH significantly reduced by 1.4 times, and the level of TBA-AP significantly increased by 1.5 times. It indicates the depletion of AOS and the activation of LPO in vaginal tissues and is accompanied by inhibition of oxygen-dependent processes.

The restoration of antioxidant protection was observed under the influence of the investigated suppositories "Melanizol" in the vaginal tissue, which is manifested by a significant increase in the level of catalase by 1.7 times and an increase in the level of G-SH by 1.3 times in comparison with animals of the CP group. A significant decrease in the level of TBA-AP was observed by 
1.8 times in the vaginal tissue under the influence of the tested suppositories "Melanizol" in comparison with a group of animals of the $\mathrm{CP}$.

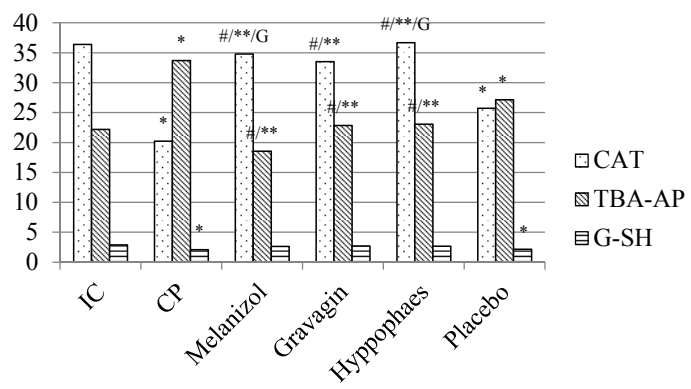

Fig. 1. The level of catalase $(\mu \mathrm{mol} / \mathrm{minute} \cdot \mathrm{g})$, TBA-AP $(\mu \mathrm{mol} / \mathrm{g})$ and $\mathrm{G}-\mathrm{SH}(\mu \mathrm{mol} / \mathrm{g})$ in the vaginal homogenate of rats on the background of nonspecific (irritative) vaginitis: * - significant

in relation to intact control, IC $(\mathrm{p}<0.05) ; * *$ - significant in relation to placebo $(\mathrm{p}<0.05)$;

$\#$ - significant in relation to the control pathology, CP $(\mathrm{p}<0.05) ; \mathrm{G}-$ significant in relation to Gravagin suppositories $(\mathrm{p}<0.05)$

On the background of nonspecific vaginitis, the suppositories "Melanizol" were not inferior to the reference drug "Hippophaes oleum suppositories" and significantly exceeded the reference suppositories "Gravagin" in terms of their effectiveness to restore catalase activity. In the ability to reduce the TBA-AP activity and to restore the G-SH level in the vaginal tissue homogenate, the tested suppositories "Melanizol" are not inferior to the reference drugs "Gravagin" and "Hippophaes oleum suppositories".

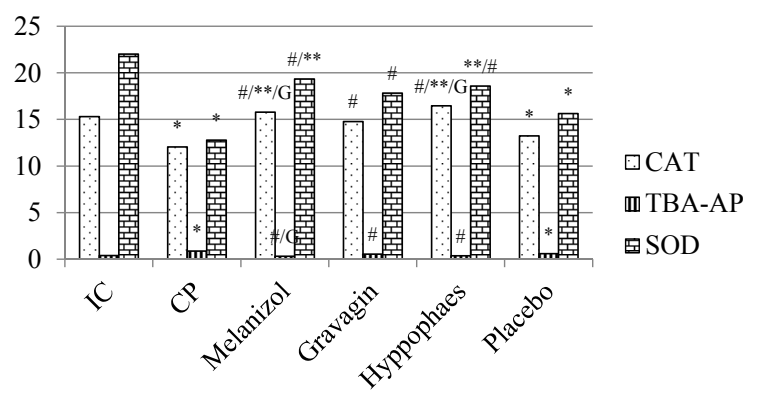

Fig. 2. The level of CAT, $\mu \mathrm{mol} /($ minute-1), TBA-AP, $\mu \mathrm{mol} / \mathrm{g}$ and SOD, conventional units (cu), used in the serum of rats on the background of nonspecific (irritative) vaginitis: * - significant in relation to intact control, IC $(\mathrm{p}<0.05)$; $* *$ - significant in relation to placebo $(\mathrm{p}<0.05)$;

\# - significant in relation to control pathology, $\mathrm{CP}(\mathrm{p}<0.05) ; \mathrm{G}-$ significantly in relation to Gravagin suppositories $(\mathrm{p}<0.05)$

On the background of experimental nonspecific (irritative) vaginitis in serum (Fig. 2), significant changes in indicators of the system LPO-AOS characteristics were noted. There are significant decrease in CAT activity by 1.3 times, significant decrease in SOD activity by 1.7 times and significant increase in the level of TBA-AP by 2.25 times in comparison with the IC group.

Recovery of antioxidant protection to the level of the values of the animals of the IC group was observed under the influence of the investigated suppositories "Melanizol" in the serum of rats with nonspecific (irritative) vaginitis. Its manifested in a significant increase in the level of CAT activity by 1.3 times and significant increase SOD activity by 1.6 times in comparison with animals of CP group. As well as, the level of TBA-AP was significantly reduced by 2.8 times as compared with animals of CP group. The data indicate a restorative effect of the studied suppositories "Melanizol" on indicators of LPO-AOS.

As a result of the experiment positive effect of suppositories "Melanizol" was noted. During the treatment with the studied drug and reference drugs, the suppositories "Melanizol" signifi- 
cantly exceeded the reference suppositories "Gravagin" in their activity to reduce TBA-AP and to increase the activity of CAT and SOD in the blood serum of rats on the background of experimental vaginitis. The suppositories "Melanizol" were not inferior to the reference drug "Hippophaes oleum suppositories" in their restoration effects on the POL-AOS system.

In animals treated with placebo, no positive effect on investigated indexes of LPO-AOS was observed both in blood serum and in vaginal tissue homogenate.

\section{Discussion}

On the background of experimental vaginitis in serum and in vaginal tissue homogenate in rats, significant changes in indicators of the LPO-AOS were noted. There are decreasing of CAT activity, decreasing of SOD activity, increasing of the level of TBA-AP in the blood serum and decreasing of CAT activity, decreasing of the level of G-SH, increasing of the level of TBA-AP in the vaginal tissue homogenate. Changes of these indicators characterize of the inflammatory process [16]. Thus, changes of these indicators show a systemic response of the body to pathological changes in the vagina, which is manifested in the depletion of AOS and activation of the LPO.

Antioxidant activity of vaginal suppositories "Melanizol" can be explained by the presence of tea tree oil in their composition, which is confirmed by literature data [17]. The antiradical activity of herbal drugs is explained by presence of phenolic compounds, monoterpene alcohols, ketones, aldehydes, carbohydrates, etc., in their composition [18]. Literature data shows that tea tree oil has a strong ability to remove free radicals and to inhibit lipid peroxidation. This is explained by the activity of the components of the oil, in particular phenols, which are able to inhibit or reduce the rate of aerobic oxidation of organic substances [17]. Data in the literature indicates that monoterpene hydrocarbons (chemical components contained within tea tree oil composition), such as terpinen-4-ol, $\gamma$-terpinene and $\alpha$-terpinene have in the structure activated methylene groups and are more active antioxidant compounds than sesquiterpenes [19].

Also, literature data show that "Metrogil" gel (contains $1 \%$ metronidazole) for external use has antioxidant properties. It can reduce the production of ROS by neutrophilic leukocytes, such as hydroxyl radicals and hydrogen peroxide, that are oxidants [20].

Thus, new vaginal suppositories "Melanizol" have antioxidant properties, because metronidazole and tea tree oil are present in their composition [17-20]. This activity is the ability to restore pathologically reduced levels of G-SH, to restore the activity of intracellular antioxidant enzymes (superoxide dismutase, catalase) and to reduce pathological level of TBA-AP in the vaginal homogenate and in the blood serum of rats with nonspecific vaginitis modeled by an intravaginal application of the mixture of turpentine oil with dimethyl sulfoxide.

This indicates a positive effect of the tested suppositories on the state of the prooxidant-antioxidant system locally and systemically. It is positive in the treatment of nonspecific vaginitis and will prevent the development of systemic complications [21].

Limitations of the study. Obtained results confirm the important role of LPO-AOS in the development of nonspecific vaginitis. New vaginal suppositories "Melanizol", containing metronidazole and tea tree oil, can restore indexes of LPO-AOS (CAT, TBA-AP, G-SH, G-SH) in the blood and in the vaginal homogenate in condition of model of experimental nonspecific vaginitis in rats. That allow us to recommend them for the further studies as medication for the treatment of nonspecific vaginitis. But this mechanism requires further detailed study.

\section{Conclusions}

In summary, studies have shown that the following conclusions can be drawn:

1. It has been experimentally proved that the new vaginal suppositories "Melanizol" in the study on the model of nonspecific (irritative) vaginitis in rats showed an antioxidant effect. Suppositories "Melanizol" significantly reduce the level of thiobarbituric acid-active products, interfering with lipid peroxidation processes, and restore the level of reduced glutathione, as well as the activity of superoxide dismutase and catalase in the blood and in the vaginal homogenate, helping to protect the cell membranes. 
2. Vaginal suppositories "Melanizol" significantly exceed the reference suppositories "Gravagin" and are not inferior to the reference drug "Hippophaes oleum Suppositories" in activity to reduce the level of thiobarbituric acid-active products, and to restore the level of reduced glutathione, as well as restoration the activity of superoxide dismutase and catalase.

3. The preliminary studies proved anti-inflammatory [22], antibacterial [23] properties of the new vaginal suppositories "Melanizol", and the antioxidant activity proved by us in this experiment allow to recommend them for the further studies as drug for the treatment of nonspecific vaginitis.

\section{Conflicts of interest}

No conflict of interest.

\section{References}

[1] Fletcher, N. M., Saed, M. G., Abu-Soud, H. M., Al-Hendy, A., Diamond, M. P., Saed, G. M. (2013). Uterine fibroids are characterized by an impaired antioxidant cellular system: potential role of hypoxia in the pathophysiology of uterine fibroids. Journal of Assisted Reproduction and Genetics, 30 (7), 969-974. doi: http://doi.org/10.1007/s10815-013-0029-7

[2] Santulli, P., Borghese, B., Lemaréchal, H., Leconte, M., Millischer, A.-E., Batteux, F. et. al. (2013). Increased Serum Oxidative Stress Markers in Women with Uterine Leiomyoma. PLoS ONE, 8 (8), e72069. doi: http://doi.org/10.1371/ journal.pone.0072069

[3] Chen, Z., Zhang, Z., Zhang, H., Xie, B. (2015). Analysis of the Oxidative Stress Status in Nonspecific Vaginitis and Its Role in Vaginal Epithelial Cells Apoptosis. BioMed Research International, 2015, 1-7. doi: http://doi.org/10.1155/2015/795656

[4] Nguyen, G. T., Green, E. R., Mecsas, J. (2017). Neutrophils to the ROScue: Mechanisms of NADPH Oxidase Activation and Bacterial Resistance. Frontiers in Cellular and Infection Microbiology, 7. doi: http://doi.org/10.3389/fcimb.2017.00373

[5] Guo, H. Y., Hu, X. M., Han, D. D., Wang, Z. P., Meng L. (2013). Lipid peroxidation and antioxidant status in vagina microenvironment of patients with several common vaginitis. Clinical and Experimental Obstetrics \& Gynecology, 40 (3), $331-336$.

[6] Lototska, O. V. (2016). Features of free oxidation in liver homogenates of rats in combined action of copper and subtoxic level of stearate potassium and sodium. Medical and Clinical Chemistry, 18 (3), 69-74. doi: http://doi.org/10.11603/ mcch.2410-681x.2016.v0.i3.6948

[7] Babak, O. Ya. (2015). Glutatyon v norme i pry patologyy: byologycheskaya rol i vozmozhnosty klynycheskogo prymenenyya. Zdorovia Ukrainy, 1. Available at: http://www.valartin.com/uploadfiles/ckfinder/files/zd_1.pdf

[8] Gorbunova, N. B., Bataj, L. E., Vodchycz, A. Y., Ulashhyk, V. S., Orlovych, V. A. (2013). Changes in activity of superoxide dismutase and catalase in blood and immunocompetent organs of rats with systemic inflammation under influence of continuous-wave low intensity visible laser radiation. Photobiology and experimental photomedicine, 1 (2), 64-70.

[9] Bezruchko, N. V., Rubczov, G. K., Ganyaeva, N. B., Kozlova, G. A., Sadovnikova, D. G. (2012). Catalase of Biological Environments of the Human Body and its Clinical Biochemical Value in Endotoxicose Estimation. TSPU Bulletin, 7 (122), 94-98.

[10] Palmeira-de-Oliveira, R., Palmeira-de-Oliveira, A., Martinez-de-Oliveira, J. (2015). New strategies for local treatment of vaginal infections. Advanced Drug Delivery Reviews, 92, 105-122. doi: http://doi.org/10.1016/j.addr.2015.06.008

[11] Yarnykh, T. G., Levachkova, Y. V., Maloshtan, L. M., Stepanova, K. O. (2011). Pat. 96646 UA. Anti-inflammatory agent in the form of pessaries with metronidazole and tea tree oil. MPK: A61P 15/00, A61K 36/61, A61K 31/4164, A61K 9/02. No. a 201001134; declareted: 04.02.2010; published: 25.11.2011, Bul. No. 22, 3.

[12] European convention for the protection of vertebral animals used for experimental and other scientific purpose (1986). Council of Europe. Strasbourg, 1-52.

[13] Rudko, A. Y., Solntseva, A. V., Usoieva, L. A., Morugina, L. V. (2011). Pat. 95741 UA. Pharmaceutical composition for the treatment of urogenital organs. MPK: A61K 31/197, A61P 15/12, A61K 31/565, A61P 15/08, A61K 9/02. No. a 201010120; declareted: 16.08.2010; published: 25.08.2011, Bul. No. 16, 11.

[14] Rybolovliev, Y. R., Rybolovliev, R. S. (1979). Dozirovanie veshhestv dlya mlekopitayushhikh po konstantam biologicheskoj aktivnosti. Reports of the USSR Academy of Sciences, 247 (6), 1513-1516.

[15] Arutyunyan, A. V., Dubinina, E. E., Zybina, N. N.; Havinson, V. H. (Ed.) (2000). Metody oczenki svobodno-radikal 'nogo okisleniya i antioksidantnoi sistemy organizma. Saint-Petersburg: IKF "Foliant", 104.

[16] Vlasov, A. A., Kovalov, G. A., Belochkina, I. V., Tynynyka, L. N., Sandomirsky, B. P. (2016). Effect of Extracts of Cryopreserved Piglet Skin Fragments on State of Pro- and Antioxidant Systems Following Skin Cryodestruction. Problems of Cryobiology and Cryomedicine, 26 (2), 170-170. doi: http://doi.org/10.15407/cryo26.02.170 
[17] Amorati, R., Foti, M. C., Valgimigli, L. (2013). Antioxidant Activity of Essential Oils. Journal of Agricultural and Food Chemistry, 61 (46), 10835-10847. doi: http://doi.org/10.1021/jf403496k

[18] Zhang, X., Guo, Y., Guo, L., Jiang, H., Ji, Q. (2018). In Vitro Evaluation of Antioxidant and Antimicrobial Activities of Melaleuca alternifolia Essential Oil. BioMed Research International, 2018, 1-8. doi: http://doi.org/10.1155/2018/2396109

[19] Gonzalez-Burgos, E., Gomez-Serranillos, M. P. (2012). Terpene Compounds in Nature: A Review of Their Potential Antioxidant Activity. Current Medicinal Chemistry, 19 (31), 5319-5341. doi: http://doi.org/10.2174/092986712803833335

[20] Nishimuta, K., Ito, Y. (2003). Effects of metronidazole and tinidazole ointments on models for inflammatory dermatitis in mice. Archives of Dermatological Research, 294 (12), 544-551. doi: http://doi.org/10.1007/s00403-002-0381-4

[21] Malchenko, O. A., Anisimova, L. V., Fedosov, M. I., Kubyshkin, A. V. (2014). The state of protooxidant-antioxidant system of the blood and muscular tissue of rats at experimental reperfusion syndrome. Taurian Medical and Biological Gazette, 17 (2 (66)), 90-93.

[22] Dolzhykova, O. V., Maloshtan, L. M. (2014). Eksperymentalne vyvchennya protyzapalnykh vlastyvostei novykh supozytoriyiv vaginalnykh «Melanizol». Problems of ecology and medicine genetics and clinical immunology. Kyiv; Lugansk, 4 (124), 161-166.

[23] Dolzhykova, O. V. Maloshtan, L. M. (2016). Microbiological predication of vaginal suppositories "Melanizol” using for nonspecific vaginitis treatment. Ukrainian biopharmaceutical journal, 3 (44), 20-23. doi: http://doi.org/10.24959/ ubphj.16.34

\title{
METHODOLOGY FOR ASSESSING THE LOGISTICS POTENTIAL OF THE FOREIGN ECONOMIC ACTIVITY OF A PHARMACEUTICAL COMPANY
}

\author{
Natali Zakharko \\ Department of Processes and Devices of chemical-pharmaceutical manufactures ${ }^{1}$ \\ paft@nuph.edu.ua \\ Rita Sahaidak-Nikitiuk \\ Department of Processes and Devices of chemical-pharmaceutical manufactures ${ }^{l}$ \\ Sagaidak_rita@ukr.net \\ Nataliya Demchenko \\ Department of Organization and Economics of Pharmacy \\ ${ }^{1}$ National University of Pharmacy \\ 53 Pushkinskay str., Kharkiv, Ukraine, 61002 \\ economica@nuph.edu.ua
}

\footnotetext{
Abstract

The aim of the article is to determine the essence of the logistics potential of a foreign trade activity of a pharmaceutical enterprise and justify the methods for determining it.

The materials used in the study include statistical data of the investigated pharmaceutical enterprises, namely JSC FF "Darnitsa", PJSC NPC "Borschagovsky Chemical and Pharmaceutical Plant”, PJSC "Pharmak”, LLC "FC Zdorovia” and JSC "Lekhim-Kharkiv". The study used methods of analysis and synthesis, generalization, content analysis, questionnaires and methods for assessing potential. The questionnaire was used to select indicators that should be part of the logistics potential of a foreign trade activity of a pharmaceutical enterprise.
} 